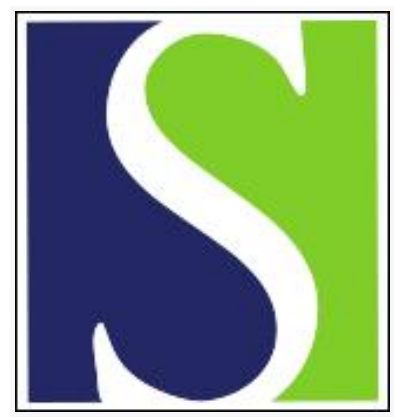

Scand J Work Environ Health 2015;41(2):140-152

https://doi.org/10.5271/sjweh.3475

Published online: 30 Dec 2014, Issue date: 01 Mar 2015

Does aerobic exercise improve or impair cardiorespiratory fitness and health among cleaners? A cluster randomized controlled trial

by Korshøj M, Lidegaard M, Skotte JH, Krustrup P, Krause N, Søgaard K, Holtermann A

A worksite aerobic exercise intervention among cleaners seems to improve cardiorespiratory fitness, aerobic workload, resting and sleeping heart rate but increases systolic blood pressure. Aerobic exercise seems to induce extensive positive cardiovascular effects, but recommendations of aerobic exercise should account for the potential cardiovascular overload of workers with high occupational physical activity and low cardiorespiratory fitness.

Affiliation: National Research Centre for the Working Environment, Lersø Parkallé 105, 2100 Copenhagen Ø, Denmark. mkl@nrcwe.dk

Refers to the following texts of the Journal: 2012;38(5):467-475

2010;36(5):357-365 1993;19(2):73-84 2007;33(6):405-424

2015;41(2):124-139

The following articles refer to this text: 2015;41(2):124-139; 2019;45(1):90-97

Key terms: Actiheart; aerobic exercise; aerobic training; aerobic workload; blood pressure; cardiorespiratory fitness; cleaner; cluster randomized controlled trial; Denmark; physical activity; physical work demand; RCT; resting heart rate; sleeping heart rate; step test; work demand; worksite intervention

This article in PubMed: www.ncbi.nlm.nih.gov/pubmed/25548798

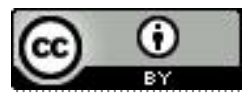




\title{
Does aerobic exercise improve or impair cardiorespiratory fitness and health among cleaners? A cluster randomized controlled trial
}

\author{
by Mette Korshøj, MSc, ${ }^{1,2}$ Mark Lidegaard, MSc, ${ }^{1}$ Jørgen H Skotte, MS, ${ }^{1}$ Peter Krustrup, PhD, ${ }^{2,3}$ Niklas \\ Krause, PhD, ${ }^{4}$ Karen Søgaard, PhD, ${ }^{5}$ Andreas Holtermann, PhD ${ }^{1,5}$
}

\begin{abstract}
Korshøj M, Lidegaard M, Skotte JH, Krustrup P, Krause N, Søgaard K, Holtermann A. Does aerobic exercise improve or impair cardiorespiratory fitness and health among cleaners? A cluster randomized controlled trial. Scand J Work Environ Health. 2015;41(2):140-152. doi:10.5271/sjweh.3475
\end{abstract}

\begin{abstract}
Objective It is unknown if aerobic exercise overloads or improves the cardiovascular system among workers with high occupational physical activity. This was investigated in a worksite randomized controlled trial (RCT) of aerobic exercise among cleaners.

Methods We randomized 116 cleaners between $18-65$ years. The aerobic exercise group ( $\mathrm{N}=57)$ performed worksite aerobic exercise ( 30 minutes twice a week) and the reference group ( $\mathrm{N}=59)$ received lectures. Cardiorespiratory fitness, blood pressure (BP) and diurnal heart rate (HR) for measuring aerobic workload [\%HR reserve $(\% \mathrm{HRR})]$ were collected at baseline and after four months. A repeated measure $2 \times 2$ multi-adjusted mixed-model design was applied to compare the between-group differences in an intention-to-treat analysis.
\end{abstract}

Results Between-group differences $(\mathrm{P}<0.01)$ were found: cardiorespiratory fitness 2.2 [standard error (SE) $0.8] \mathrm{ml} \mathrm{O}_{2} \times \mathrm{min}^{-1} \times \mathrm{kg}^{-1}$ [95\% confidence interval $(95 \% \mathrm{CI})$ 0.6-3.8], aerobic workload -3.5 (SE 1.2) \%HRR (95\% CI -5.9- -1.0), resting HR -3.8 (SE 1.2) bpm (95\% CI -6.1- -1.4), sleeping HR -3.8 (SE 1.1) bpm (95\% CI - 5.9- -1.7), and systolic BP 3.6 (SE 1.3) $\mathrm{mmHg}(95 \%$ CI 1.1-6.0).

Conclusions Worksite aerobic exercise seems to improve cardiorespiratory fitness, aerobic workload, and resting and sleeping HR, but increase systolic BP among cleaners. Beneficial physiological cardiovascular effects are seen from aerobic exercise, but also a harmful effect is evident. Therefore, recommendations should take into consideration the potential cardiovascular overload from additional aerobic exercise on workers with high levels of occupational physical activity.

Key terms Actiheart, aerobic training, aerobic workload, blood pressure, Denmark, physical activity, physical work demand, RCT, resting heart rate, sleeping heart rate, step test, work demand, worksite intervention

A recent meta-analysis (1) reports that moderate and high levels of occupational physical activity increase the risk of cardiovascular disease (CVD). The risk for CVD is especially strong among workers who have high levels of occupational physical activity combined with low cardiorespiratory fitness $(2,3)$. Compared to a worker with high cardiorespiratory fitness, workers with low cardiorespiratory fitness experience a higher relative aerobic workload when performing the same physical work task (4). A high relative aerobic workload accelerates progression of arteriosclerosis $(5,6)$, and increases the risk of myocardial infarction (7). Therefore, a balanced relationship between occupational physical activity and cardiorespiratory fitness of the worker is recommended for reducing overall risk of work-related cardiovascular overstrains $(8,9)$. Specifically, the International Labour Organization has recommended that the average aerobic workload should not exceed $30 \%$ during an 8 -hour working day $(10,11)$.

1 National Research Centre for the Working Environment, Copenhagen Ø, Denmark.

2 Department of Nutrition, Exercise and Sports, Copenhagen Centre for Team Sport and Health, University of Copenhagen, Copenhagen N, Denmark.

3 Sport and Health Sciences, College of Life and Environmental Sciences, St. Luke's Campus, University of Exeter, Exeter, United Kingdom.

4 Department of Environmental Health Sciences and Department of Epidemiology, Fielding School of Public Health, Southern California NIOSH Education and Research Center, University of California Los Angeles, Los Angeles, CA, USA.

5 Institute of Sports Science and Clinical Biomechanics, University of Southern Denmark, Odense M, Denmark.

Correspondence to: Mette Korshøj, MSc, National Research Centre for the Working Environment, Lersø Parkallé 105, 2100 Copenhagen Ø, Denmark. [Email: mkl@nrcwe.dk] 
Heart rate reserve (HRR) is a validated objective measure of relative aerobic workload, ie, the relationship between physical work demands and a worker's aerobic capacity (cardiorespiratory fitness) $(12,13)$. HRR is assessed by resting heart rate, which depends on cardiorespiratory fitness, and maximal heart rate $\left(\mathrm{HR}_{\max }\right)$, which depends on age (14), and is thereby applicable across workers of varying age and aerobic capacities (15).

An imbalance between physical work demands and cardiorespiratory fitness can be targeted either by reducing physical work demands or enhancing cardiorespiratory fitness $(3,9)$ or the combination thereof. To our knowledge, a reduction of the relative aerobic workload by aerobic exercise has not yet been shown to be successful among blue-collar workers. High quality aerobic exercise interventions among workers with high levels of occupational physical activity are few and with conflicting findings (16-19), especially regarding cardiovascular risk factors such as cardiorespiratory fitness and blood pressure (BP) $(20,21)$.

Actually, it has been discussed in the literature, whether introducing aerobic exercise could overload and thereby impair the cardiovascular system among workers with high levels of occupational physical activity $(22,23)$. Workers with high levels of occupational physical activity often have a low cardiorespiratory fitness (4, 24-26) and limited ability for pauses and restitution, which may result in an increased risk of overloading and impairing the cardiovascular system (22). Thus, an aerobic exercise intervention may affect factors for cardiovascular disease both positively and negatively. Clearly, it is important to investigate if aerobic exercise among workers with high occupational physical activity will reduce their cardiovascular risk.

Cleaning is characterized by high levels of occupational physical activity $(24,27,28)$. Cleaners' cardiorespiratory fitness has been described as relatively low and consequently a high relative aerobic workload is expected $(4,28)$. Moreover, a high prevalence of other cardiovascular risk factors including hypertension and obesity $(25,29)$, and an overall elevated CVD risk have been reported among cleaners $(30,31)$. Classical interventions have aimed to lower the relative aerobic workload among cleaners through the ergonomic improvement of tools (32-34). Additionally, a natural experiment has been used to evaluate work technique and organizational aspects in relation to relative aerobic workload (28). However, these studies did not find significant reductions in the relative aerobic workload by intervening on the physical work demands with ergonomic or organizational interventions. An alternative approach to decrease the aerobic workload is an intervention aimed at enhancing the cardiorespiratory fitness with aerobic exercise. Cleaners therefore constitute a suitable study population to investigate if worksite aerobic exercise will improve cardiorespiratory fitness, relative aerobic workload and cardiovascular risk factors among workers with high occupational physical activity.

The main objective of this study was to investigate if a worksite aerobic exercise intervention will improve cardiorespiratory fitness, relative aerobic workload, and other cardiovascular risk factors in a cluster randomized controlled trial (RCT) among cleaners. The main hypotheses of the study were that the worksite aerobic exercise intervention would (i) increase the cardiorespiratory fitness, (ii) decrease the aerobic workload, and (iii) not modify BP or resting and sleeping heart rate (testing the null hypothesis).

\section{Methods}

\section{Study design}

As part of a cluster RCT, the intervention was divided into two phases with different aims. The aim of phase one, from baseline to 4-months follow-up, was to evaluate the efficacy of the intervention on cardiorespiratory fitness, aerobic workload, and cardiovascular risk factors. Outcomes were measured at baseline, and again at 4 and 12 months after baseline (35). The present paper reports the results from the first intervention phase (0-4 months) on cardiorespiratory fitness and cardiovascular risk factors.

The Danish Data Protection Agency and the Ethics Committee for the regional capital in Denmark (journal number H-2-2011-116) approved the study, which was conducted in accordance with the Helsinki Declaration and is registered as ISRCTN86682076 in the Current Controlled Trials (www.controlled-trials.com/ ISRCTN86682076).

\section{Recruitment of worksites and study participants}

Cleaning companies in the suburban area of Copenhagen, Denmark, were recruited via direct phone or email contact to the management. If the company expressed an interest in the project, a meeting was arranged between the research group and company management. If the company agreed to participate, written information about the aim, content and activities involved in participation (project activities) was distributed to all employed cleaners, and they were also invited to an information meeting. Employed cleaners completed a screening questionnaire, collecting background information such as ethnicity, smoking status, job seniority, and levels of physical activity during working hours and leisure time (35). Additionally, the cleaners were asked if they wished to participate in the study, and if not, the reason why. 
At company level, study inclusion criteria were staff of $>50$ employed cleaners and management's permission for cleaners to participate in the project activities during paid working time. At participant level, inclusion criteria were age 18-65 years, employment as cleaning assistant for $>20$ hours per week, and signed informed consent to participate in the study.

The only exclusion criterion for participating in the intervention was pregnancy. However, the following conditions excluded participation in the specific physical capacity tests: congestive heart failure, hospital admission for myocardial infarction or acute coronary syndrome within the last two years, angina pectoris, severe hypertension $(\geq 160 / \geq 100 \mathrm{mmHg})$, serious or chronic illness, severe trauma, frequent migraine, and fever on the day of testing. Allergy to adhesive plasters excluded participation in diurnal HR measurements.

\section{Randomization}

Randomization was performed at cluster level. A cluster was set within strata, and stratums were formed according to which manager the participant reported. Clusters were balanced on geographical work location, gender, age, and job seniority. To minimize imbalance across several strata, the clusters were paired according to number of participants, gender, age, and job seniority, within each stratum. A stratum was named alphabetically, and a cluster was named consecutively within each stratum. The randomization was carried out by a researcher blinded to the identity of the participants, strata, and clusters. Three researchers supervised the reliability of the randomization procedure. All paired clusters assigned to the specific stratum were drawn from an opaque, tossed bag and were alternately allocated to either reference or aerobic exercise group, depending on the flip of a coin. Tails decided allocation of the first of the two drawn paired clusters to the reference group and heads to the aerobic exercise group. The second of the two drawn paired clusters was allocated to the group opposite to the first (35).

\section{Intervention}

During the intervention, the reference group was offered two lectures of two hours each. The aerobic exercise group was offered supervised aerobic exercise of $2 \times 30$ minutes/week, in total 32 sessions. All project activities were carried out during paid working hours, at or nearby the worksite. The lectures addressed healthy living, but not physical activity, and participants were invited to suggest topics. The aerobic exercise was aimed to be performed at an intensity of $\geq 60 \%$ of maximal oxygen consumption $\left(\mathrm{VO}_{2 \max }\right)$ for enhancing the cardiorespiratory fitness (36). Through a modified intervention map- ping approach (37), the aerobic exercises were tailored to each of the enrolled companies individually (35). The following two key points determined the intervention protocol: (i) Feasibility: it should be possible to execute the aerobic exercise at or nearby the enrolled company, during paid working hours; (ii) Motivation: the intervention activities should apply to the participants' preferences. In order to meet these requirements, company-specific intervention protocols were developed in collaboration between researchers and representatives from the company management, employed cleaners, and union.

\section{Data collection}

All participants were tested at baseline and after the 4-months intervention period. The test consisted of a structured interview, physical testing of health- and capacity-related measures and objective diurnal measures of HR (35). Participants got instant feedback from the physical testing. Participants were encouraged to contact a physician if their systolic or diastolic BP exceeded recommended levels ( $\geq 140$ and/or $\geq 90 \mathrm{mmHg}$ ) (38). HR was measured over four days (mostly two working and two non-working days). Participants were instructed in how to wear the monitor and to write a log of working hours, sleeping time, and time periods spent without monitors. During the diurnal measurements, participants were asked to live their normal every-day life.

The interview assessed sex, education, occupational group, employment status, job seniority, level of perceived exertion during work on a 6-20 scale (39), occupational and leisure-time physical activity (40), general health (41), diagnosed illnesses, and daily use of heart disease or anti-hypertension medication. The interview approach was chosen with the aim of collecting background data without missing observations because many of the participants are not ethnic Danes and have poor reading and writing skills.

Physical examinations measured body weight $(\mathrm{kg})$ and fat (\%) with a bioelectric-impedance-analysis tool, Tanita BC418, (Tanita Corp, Toyko, Japan), height with Seca model 213 1721009, and waist circumference with Seca model 201 (Seca, Hamburg, Germany). The waist was defined as the narrowest point between the lowest rib and the iliac crest $(42,43)$. Body mass index (BMI), was calculated as body weight $(\mathrm{kg})$ divided by body height squared $\left(\mathrm{m}^{2}\right)(42)$. Three BP measurements were collected with Omron M6 Comfort (Omrom Healthcare, Kyoto, Japan) on the upper-left arm after minimum 15 minutes of sitting rest. Level of cardiorespiratory fitness was estimated by a sub-maximal step test (44) conducted on a bench of $30 \mathrm{~cm}$ height for females and $35 \mathrm{~cm}$ for males. Step frequency was increased from 0.2 steps per second to maximal 0.8 steps per second, at maximal six 
minutes of testing time. The step test was terminated when the participant could no longer keep the stepping rhythm or properly extend the knee. Measurements were conducted with participants wearing light clothes and no shoes.

The diurnal measurements of HR were performed with Actiheart (Camntech, Cambridge, UK). Actiheart is validated for measurement of HR, HR variability, and estimation of energy expenditure in the field $(45,46)$. The electrocardiographic raw signals are measured with a sensitivity of $0.25 \mathrm{mV}$, and $\mathrm{HR}$ is calculated as the number of $R$ peaks in the QRS complex per minute. Before measurement, the Actiheart monitor was initialized by gender and age, and mounted with ag-ag-cl pre-gelled electrodes (Ambu blue sensor VL-00-S/25, Ambu Ballerup, Denmark) at one of the validated body positions (47).

During the intervention period, the instructor registered participation in the aerobic exercise group at every session. Additionally, Actiheart was used to measure the intensity of the aerobic exercise every fourth week at one session, which was calculated in percent of HRR (48). HRR was defined as the difference between the estimated $\mathrm{HR}_{\max }$ (14) and the sleeping HR (SHR), with SHR defined as the $10^{\text {th }}$ lowest recorded HR value during 24 hours (49). HRR represents the workers relative aerobic workload as the range between SHR and $\mathrm{HR}_{\max }$ (48). HRR is based on measured HR throughout the 24-hour measurements, and reflects both physical and psychosocial demands (50).

\section{Sample size}

The power calculation, performed prior to the study, showed that the expected increase in cardiorespiratory fitness of $4 \%$ would take 52 participants in each of the two intervention groups to show significance at a level of 0.05. Sample size calculations assumed recruitment of $40 \%$ of eligible cleaners and a dropout rate of $30 \%$ during the intervention (35).

\section{Analysis}

The primary outcome of this trial is 4-months change in cardiorespiratory fitness $\left(\mathrm{ml} \mathrm{O}_{2} \times \mathrm{min}^{-1} \times \mathrm{kg}^{-1}\right)$. Secondary outcomes are 4-months changes in relative aerobic workload (\%HRR), RHR in beats-per-minute (bpm), SHR (bpm), and resting systolic BP ( $\mathrm{mmHg}$ ). Only HR measurements with beat error of $\leq 50 \%$ were included to meet the data quality criteria set by Skotte and colleagues (51).

Ethnicity was classified as western or non-western based on country of birth. All European countries, Australia, Canada, and USA were considered western. The mean of the second and third BP measurement was calculated and evaluated as a secondary outcome.

\section{Statistical analysis}

Statistical analyses were performed using SPSS statistics software (version 21) (IBM Corp, Armonk, NY, US) and the SAS statistical software for Windows (version 9.3) (SAS Institute, Cary, NC, US).

All analyses were performed according to the intention-to-treat principle, in which all randomized participants are included in the statistical analyses (52). Missing values were imputed for neither outcome nor covariate variables (53). Both within- and betweengroup 4-month changes of all outcomes were computed with standard errors (SE) and $95 \%$ confidence intervals (95\% CI). Differences in 4-month changes of all outcomes were analyzed in repeated-measures $2 \times 2$ mixed -model design. Independent categorical variables (fixed factors) were group (aerobic exercise and reference), measurement time (baseline and 4-month follow-up), and the interaction between group and measurement time. Participants were entered in the model as a random effect nested in clusters to account for the cluster-based randomization. Covariates were chosen based on: baseline differences between groups, theoretically considered confounders, and their statistical association with the group and measurement time. The following covariates (reference value in parenthesis) were entered into the mixed models in the following incremental steps: (i) baseline value of the respective outcome, (ii) age, sex (male), daily use of antihypertension and/or heart medication (none), smoking status (never smoking and/ or currently non-smoking), and either level of leisuretime physical activity ( $<2$ hours/weeks light activity) or baseline cardiorespiratory fitness. The intervention effect estimates were reported as between-group mean difference, SE, 95\% CI, and P-value.

A sensitivity analysis excluding participants reporting use of antihypertension and/or heart medication on a daily basis was performed using the same statistical methods. A secondary between-group analysis stratified on baseline level of aerobic workload (low $<30 \% \mathrm{HRR}$ or high $\geq 30 \% \mathrm{HRR}$ ) was conducted.

\section{Results}

\section{Flow of participants}

All of the three contacted companies agreed to participate. Researchers presented the study to 250 cleaners in the companies. Information meetings were arranged jointly with the company's obligatory employee meetings. In total, 137 (57\%) wished to participate and were invited to the baseline measurement. Of those, 116 underwent baseline measurements and were random- 
ized, with 57 assigned to the aerobic exercise group and 59 to the reference group. The main self-reported reasons for non-participation were lack of time $(40 \%)$ or not finding the project relevant $(11 \%)$.

After baseline measurements, 34 (29\%) participants (19 from the aerobic exercise and 15 from the reference group) dropped out of the study and were lost to followup (figure 1). The main reasons given for dropping out were difficulties in making time for the project activities during working hours (24\%) and being too tired to participate (18\%); $27 \%$ did not give any reason.

\section{Compliance}

The $29 \%$ drop out was within the expected $30 \%$. Participants randomized to the aerobic exercise participated on average in $51 \%$ of the planned sessions during the intervention period, including five participants with zero adherences. Participants not lost to follow-up, participated in $64 \%$ of the planned sessions, none with zero adherences. The reasons for missed sessions in the aerobic exercise group were vacation and days off $(52 \%)$, medical appointments, hospitalization and/or sick leave $(30 \%)$ or meetings at work, courses and/or urgent job tasks (18\%). Overall, 94\% of the planned sessions were offered as planned.

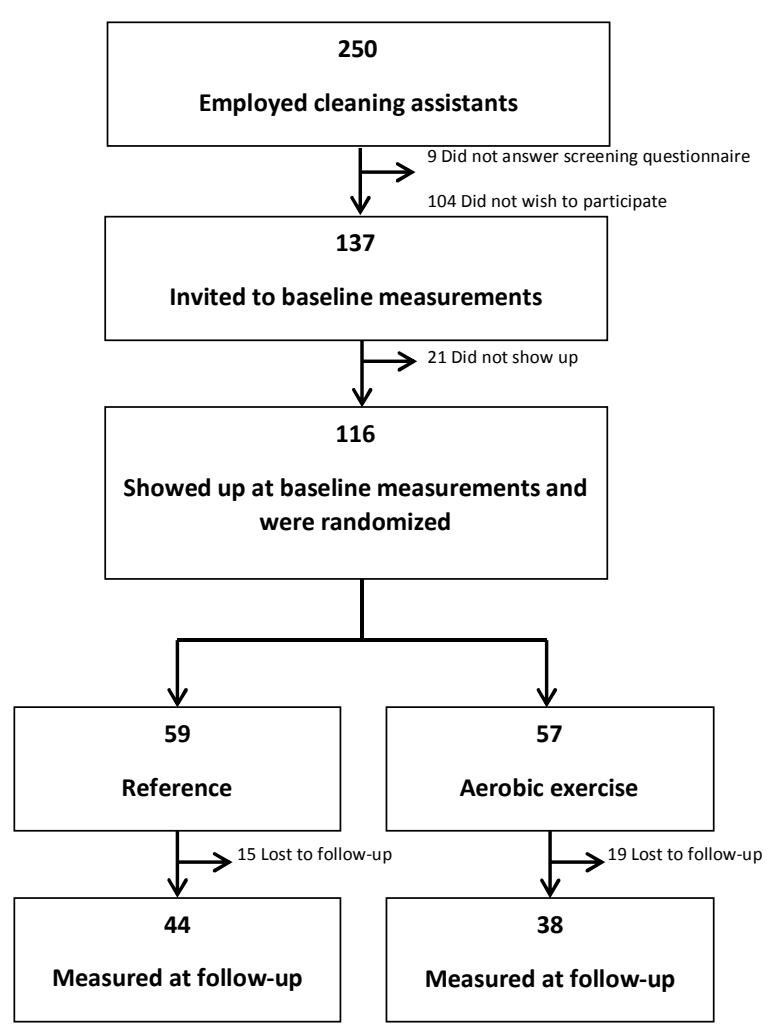

Figure 1. Flow chart of the participants in the study
After every fourth week of the intervention, the heart rate was monitored during the aerobic exercise session yielding an average HRR of 67 [standard deviation (SD) 13$] \%$.

\section{Baseline characteristics of the study population}

The baseline characteristics of the study population are presented in table 1. Participants randomized to the intervention were mainly immigrants; $86 \%$ stated having a place of birth other than Denmark, $62 \%$ of whom were non-western.

No statistical or numerically significant differences between the randomized population and the population participating at both baseline and follow-up measurements (complete to follow-up) were found (data not shown), except for lower frequency of $>12$ years of education in the aerobic exercise group (5.3\%) compared to the reference group (16.9\%).

Compared to the randomized population $(\mathrm{N}=116)$, the $19(33 \%)$ participants lost to follow-up in the exercise group were 2.5 years younger, included $1.7 \%$ fewer females, had a mean of $1 \mathrm{bpm}$ higher SHR, 3.5\% fewer used antihypertension and/or heart medication on a daily basis, $19.7 \%$ more were current smokers, and $5.2 \%$ more stated to have a leisure-time physical activity level $\geq 2$ hours of moderate activity per week. Within the reference group, the $16(25 \%)$ participants lost to follow-up were 0.9 years younger, included $3 \%$ fewer females, had a mean of $0.9 \mathrm{bpm}$ higher SHR, a mean of $3.2 \mathrm{bpm}$ higher RHR, $1 \mathrm{mmHg}$ higher systolic BP, 3.5\% less of them used antihypertension and/or heart medication on a daily basis, $14.6 \%$ more of them were current smokers, and $3.1 \%$ more of them stated to have a leisure time physical activity level of $<2$ hours of moderate activity per week.

The objective baseline HRR measures revealed that $51 \%$ of the randomized population exceeded recommended levels of relative aerobic workload during working hours $(10,11)$.

\section{Intervention effects - within group}

Fully adjusted within group changes of all outcomes during follow-up are shown in table 2. Cardiorespiratory fitness increased significantly by $7.3 \%$ or 1.8 (SE 0.7 ) $\mathrm{ml}$ $\mathrm{O}_{2} \times \mathrm{min}^{-1} \times \mathrm{kg}^{-1}(95 \%$ CI $0.3-3.2, \mathrm{P}=0.02)$ in the aerobic exercise group and was reduced by $0.01 \%$ or -0.3 (SE $0.7) \mathrm{ml} \mathrm{O}_{2} \times \mathrm{min}^{-1} \times \mathrm{kg}^{-1}(95 \% \mathrm{CI}-1.6-1.1, \mathrm{P}=0.71)$ in the reference group.

Relative aerobic workload decreased in the aerobic exercise group and increased in the reference group. Both RHR and SHR decreased in the aerobic exercise group and increased in the reference group.

Systolic BP increased significantly by 5.2 (SE 1.2) $\mathrm{mmHg}(95 \% \mathrm{CI} 2.8-7.6, \mathrm{P}<0.01)$ in the aerobic exercise 
Table 1. Description of the randomized study population at baseline $(\mathrm{N}=116)$, stratified by intervention group. Differences between aerobic exercise and reference groups were analyzed with student's t-test for continuous variables and with Chi² test for categorical variables. [SD=standard deviation; $\mathrm{BP}=$ blood pressure; $\mathrm{HR}=$ heart rate; HRR=heart rate reserve].

\begin{tabular}{|c|c|c|c|c|c|c|c|c|c|c|c|c|}
\hline & \multicolumn{4}{|c|}{ Randomized group ( $\mathrm{N}=116)$} & \multicolumn{4}{|c|}{ Aerobic exercise $(\mathrm{N}=57)$} & \multicolumn{4}{|c|}{ Reference $(\mathrm{N}=59)$} \\
\hline & Mean & SD & $\mathrm{N}$ & $\%$ & Mean & SD & $\mathrm{N}$ & $\%$ & Mean & SD & $\mathrm{N}$ & $\%$ \\
\hline Age (years) & 45.3 & 8.6 & & & 44.9 & 9.2 & & & 45.7 & 8.1 & & \\
\hline Sex (females) & & & 88 & 75.9 & & & 43 & 75.4 & & & 45 & 76.3 \\
\hline Height $(\mathrm{cm})$ & 162.6 & 8.8 & & & 163.1 & 9.2 & & & 162.2 & 8.4 & & \\
\hline Weight (kg) & 70.7 & 14.1 & & & 69.7 & 12.7 & & & 71.7 & 15.4 & & \\
\hline Body mass index $\left(\mathrm{kg} / \mathrm{m}^{2}\right)$ & 26.7 & 4.5 & & & 26.2 & 4.0 & & & 27.1 & 4.9 & & \\
\hline Systolic BP (mmHg) & 122.7 & 21.7 & & & 125.2 & 25.1 & & & 120.3 & 17.5 & & \\
\hline Diastolic BP (mmHg) & 82.7 & 12.6 & & & 83.7 & 14.2 & & & 81.7 & 10.8 & & \\
\hline Body fat & & 8.6 & & 31.6 & & 8.3 & & 31.1 & & 8.9 & & 32.1 \\
\hline Waist circumference (cm) & 87.6 & 11.1 & & & 86.7 & 11.0 & & & 88.4 & 11.2 & & \\
\hline Cardiorespiratory fitness $\left(\mathrm{ml}_{2} \times \mathrm{min}^{-1} \times \mathrm{kg}^{-1}\right)$ & 24.9 & 6.6 & & & 24.8 & 5.8 & & & 25.0 & 7.2 & & \\
\hline Resting HR (beats/minute) & 71.3 & 14.8 & & & 71.7 & 10.6 & & & 70.5 & 8.8 & & \\
\hline Sleeping HR (beats/minute) & 49.5 & 5.8 & & & 49.2 & 6.5 & & & 49.7 & 5.1 & & \\
\hline Aerobic workload (\% HRR) & & 7.2 & & 30.9 & & 6.7 & & 30.1 & & 7.5 & & 31.7 \\
\hline Steps taken per working hour (steps/hour) & 1316 & 417 & & & 1271 & 343 & & & 1357 & 473 & & \\
\hline Rating of perceived exertion during working hours & 13.0 & 3.3 & & & 12.9 & 3.2 & & & 13.1 & 3.3 & & \\
\hline Job seniority (years) & 11.9 & 7.8 & & & 12.3 & 8.7 & & & 11.5 & 6.8 & & \\
\hline Current smoker & & & 28 & 24.1 & & & 13 & 22.8 & & & 15 & 25.4 \\
\hline Education ( $\%>12$ years of education) & & & 13 & 11.2 & & & 3 & $5.3^{\mathrm{a}}$ & & & 10 & $16.9^{\mathrm{a}}$ \\
\hline Ethnicity (\% non western) & & & 72 & 62.1 & & & 40 & 70.2 & & & 32 & 54.2 \\
\hline Daily use of antihypertension and/or heart medication & & & 14 & 12.1 & & & 8 & 14.0 & & & 6 & 10.2 \\
\hline $\begin{array}{l}\text { Leisure-time physical activity ( } \%<2 \text { hours/weeks light } \\
\text { activity or light activity } 2-4 \text { hours/weeks) }\end{array}$ & & & 84 & 72.4 & & & 45 & 78.9 & & & 39 & 66.1 \\
\hline $\begin{array}{l}\text { Physical activity at work (\% having standing/walking work } \\
\text { including lifts and strenuous physical work) }\end{array}$ & & & 70 & 60.3 & & & 36 & 63.2 & & & 34 & 57.6 \\
\hline
\end{tabular}

a Statistical significant difference between subgroups $(\mathrm{P} \leq 0.05)$.

group and less [1.3 (SE 1.1) $\mathrm{mmHg}$, non-significant] in the reference group. Diastolic BP changes were $<1 \mathrm{mmHg}$ in both groups.

\section{Intervention effects - between-groups}

The between-group differences in 4-months change of primary and secondary outcomes are reported in table 3 for both model 1 , adjusting for the baseline value of the respective outcome, and the fully-adjusted model 2. Effect sizes differed considerably (up to a factor of 4.4 or $444 \%$ in the case of aerobic workload) between models 1 and 2 .

The fully adjusted (model 2) between-group difference in cardiorespiratory fitness change was 2.2 (SE $0.8) \mathrm{ml} \mathrm{O}_{2} \times \mathrm{min}^{-1} \times \mathrm{kg}^{-1}(95 \%$ CI $0.6-3.8, \mathrm{P}<0.01)$ in the aerobic exercise group relative to the reference group. This corresponds to an $8.8 \%$ increase relative to the overall baseline mean in the randomized population.

Significant between-group differences were also found for changes in aerobic workload of -3.5 (SE 1.2) \%HRR (95\% CI $-5.9--1.0, \mathrm{P}<0.01$ ) (model 2). This corresponds to an $11.3 \%$ decrease relative to the overall baseline mean in the randomized population.

Significant between-group difference in change of RHR was -3.8 (SE 1.2) bpm (95\% CI -6.1- -1.4, P<0.01) (model 2). Relative to the overall baseline mean in the randomized population, this decrease corresponds to
$5.3 \%$ (4 bpm). Similar results are seen for the change of SHR, the between-group difference was -3.8 (SE 1.1) bpm (95\% CI -5.9- -1.7, P<0.01) (model 2). Relative to the overall baseline mean in the randomized population, this corresponds to a reduction of $7.7 \%$ (4 bpm).

The change in systolic BP showed significant between-group differences of 3.6 (SE 1.3) $\mathrm{mmHg}(95 \%$ CI 1.1-6.0, $\mathrm{P}<0.01$ ) (model 2). Relative to the overall baseline mean in the randomized population, this change corresponds to a $2.9 \%(4 \mathrm{mmHg})$ increase. Diastolic BP changes did not differ significantly between groups.

\section{Sensitivity analysis}

A first sensitivity analyses excluded the 14 participants with daily use of antihypertension and/or heart medication and yielded between-group differences during follow-up comparable to results in the entire randomized population $(\mathrm{N}=116)$. For the 102 participants without such medication, the between-group changes from baseline to follow-up corresponded to a significant $6.0 \%$ increase in cardiorespiratory fitness for the aerobic exercise group, in the fully adjusted model (model 2).

In a second sensitivity analysis, model 2 for the aerobic workload was additionally adjusted for baseline and 4-month change in steps walked per hour of work (ie, indication of physical work demands), resulting in only a slightly $(0.9 \%)$ higher estimate of change in relative 
Table 2. Within group 4-month changes in cardiorespiratory fitness and secondary outcomes among cleaners ( $\mathrm{N}=116)$ by intervention group. Results are based on a mixed-model analysis with step-wise entry of covariates in two models. [ $95 \% \mathrm{Cl}=95 \%$ confidence interval; $\mathrm{SE}=$ standard error; $\mathrm{HR}=$ heart rate; $\mathrm{HRR}=$ heart rate reserve; $\mathrm{BP}=$ blood pressure]

\begin{tabular}{|c|c|c|c|c|c|c|c|c|}
\hline & \multicolumn{4}{|c|}{ Model $1^{\text {a }}$} & \multicolumn{4}{|c|}{ Model $2^{\mathrm{b}}$} \\
\hline & $\Delta$ & SE & $95 \% \mathrm{Cl}$ & P-value & $\Delta$ & SE & $95 \% \mathrm{Cl}$ & P-value \\
\hline \multicolumn{9}{|l|}{ Aerobic exercise group $(\mathrm{N}=57)$} \\
\hline \multicolumn{9}{|l|}{ Primary outcome } \\
\hline $\begin{array}{l}\text { Cardiorespiratory fitness } \\
\left(\mathrm{ml} \mathrm{O}_{2} \times \mathrm{min}^{-1} \times \mathrm{kg}^{-1}\right)\end{array}$ & 1.61 & 0.73 & $0.17-3.05$ & 0.03 & 1.75 & 0.73 & $0.30-3.20$ & 0.02 \\
\hline \multicolumn{9}{|l|}{ Secondary outcomes } \\
\hline Aerobic workload (\% of HRR) & -0.57 & 0.99 & $-2.52-1.39$ & 0.57 & -1.68 & 1.11 & $-3.90-0.54$ & 0.14 \\
\hline Resting HR (beats/minute) & -1.72 & 1.06 & $-3.80-0.36$ & 0.11 & -1.37 & 1.14 & $-3.63-0.89$ & 0.23 \\
\hline Sleeping HR (beats/minute) & -0.80 & 0.77 & $-2.32-0.73$ & 0.30 & -0.79 & 0.94 & $-2.66-1.08$ & 0.40 \\
\hline Systolic BP (mmHg) & 2.79 & 1.38 & $0.07-5.51$ & 0.04 & 5.18 & 1.20 & $2.81-7.55$ & $<0.01$ \\
\hline Diastolic BP (mmHg) & -2.09 & 0.86 & $-3.79--0.38$ & 0.02 & 0.15 & 0.91 & $-1.64-1.94$ & 0.87 \\
\hline \multicolumn{9}{|l|}{ Reference group $(\mathrm{N}=59)$} \\
\hline \multicolumn{9}{|l|}{ Primary outcome } \\
\hline $\begin{array}{l}\text { Cardiorespiratory fitness } \\
\left(\mathrm{ml} \mathrm{O}_{2} \times \mathrm{min}^{-1} \times \mathrm{kg}^{-1}\right)\end{array}$ & -0.24 & 0.68 & $-1.57-1.10$ & 0.72 & -0.25 & 0.68 & $-1.59-1.08$ & 0.71 \\
\hline \multicolumn{9}{|l|}{ Secondary outcomes } \\
\hline Aerobic workload (\% of HRR) & 0.03 & 0.90 & $-1.75-1.80$ & 0.98 & 1.72 & 0.89 & $-0.05-3.49$ & 0.06 \\
\hline Resting HR (beats/minute) & 0.20 & 1.04 & $-1.84-2.25$ & 0.85 & 2.28 & 1.06 & $0.20-4.37$ & 0.03 \\
\hline Sleeping HR (beats/minute) & 0.88 & 0.69 & $-0.48-2.24$ & 0.20 & 2.90 & 0.77 & $1.37-4.43$ & $<0.01$ \\
\hline Systolic BP (mmHg) & 0.91 & 1.34 & $-1.73-3.56$ & 0.50 & 1.30 & 1.09 & $-0.86-3.46$ & 0.24 \\
\hline Diastolic BP (mmHg) & -0.02 & 0.84 & $-1.86-1.45$ & 0.81 & -0.05 & 0.82 & $-1.68-1.58$ & 0.95 \\
\hline
\end{tabular}

Table 3. Between-groups difference from baseline to 4-months follow-up on cardiorespiratory fitness and secondary outcomes in the randomized population of cleaners $(\mathrm{N}=116)$. Results are based on a mixed-model analysis with step-wise entry of covariates in two models. [95\% Cl=95\% confidence interval; $\mathrm{SE}=$ standard error; $\mathrm{HR}=$ heart rate; $\mathrm{HRR}=$ heart rate reserve; $\mathrm{BP}=$ blood pressure]

\begin{tabular}{|c|c|c|c|c|c|c|c|c|c|c|}
\hline & \multicolumn{5}{|c|}{ Model $1^{\text {a }}$} & \multicolumn{5}{|c|}{ Model $2^{\mathrm{b}}$} \\
\hline & $\Delta$ & SE & $95 \% \mathrm{Cl}$ & P-value & $\mathrm{N}$ & $\Delta$ & SE & $95 \% \mathrm{Cl}$ & P-value & $\mathrm{N}$ \\
\hline \multicolumn{11}{|l|}{ Primary outcome } \\
\hline $\begin{array}{l}\text { Cardiorespiratory fitness } \\
\left(\mathrm{ml} \mathrm{O}_{2} \times \mathrm{min}^{-1} \times \mathrm{kg}^{-1}\right)\end{array}$ & 1.81 & 0.78 & $0.27-3.36$ & 0.02 & 86 & 2.21 & 0.79 & $0.64-3.78$ & $<0.01$ & 85 \\
\hline \multicolumn{11}{|l|}{ Secondary outcomes } \\
\hline Aerobic workload (\% of HRR) & -0.75 & 1.12 & $-2.96-1.47$ & 0.50 & 85 & -3.46 & 1.23 & $-5.92--1.00$ & $<0.01$ & 61 \\
\hline Resting $\mathrm{HR}$ (beats/min) & -1.70 & 1.15 & $-3.97-0.56$ & 0.14 & 115 & -3.75 & 1.20 & $-6.13--1.38$ & $<0.01$ & 85 \\
\hline Sleeping HR (beats/min) & -1.71 & 0.87 & $-3.43-<0.01$ & 0.05 & 87 & -3.82 & 1.05 & $-5.91--1.73$ & $<0.01$ & 63 \\
\hline Systolic BP (mmHg) & 2.28 & 1.49 & $-0.66-5.22$ & 0.13 & 116 & 3.57 & 1.25 & $1.10-6.04$ & $<0.01$ & 86 \\
\hline Diastolic BP (mmHg) & -1.66 & 0.93 & $-3.50-0.17$ & 0.08 & 116 & -0.03 & 0.95 & $-1.90-1.84$ & 0.98 & 86 \\
\hline
\end{tabular}

a Model 1 is adjusted for baseline value of the respective outcome.

${ }^{\mathrm{b}}$ For the primary outcome: Model 2 is additionally adjusted for age, sex, daily use of antihypertension and/or heart medication, smoking status and baseline leisure time physical activity. For the secondary outcomes: Model 2 is additionally adjusted for age, sex, use of antihypertension and/or heart medication, smoking status and baseline cardiorespiratory fitness. The $\mathrm{N}$ differs between the different outcomes due to missing observations in covariate and/or outcome variables.

aerobic workload [-3.6 SE 1.6), 95\% CI -0.33- -6.87, $\mathrm{P}=0.03]$. Moreover, no difference in number of steps taken per hour at work from baseline to follow-up was found in either of the groups.

A secondary between-group analysis stratified on baseline level of aerobic workload (low $<30 \%$ HRR or high $\geq 30 \% \mathrm{HRR}$ ) and adjusted for the same covariates as in model 2. Those having a high level of aerobic workload at baseline $(\mathrm{N}=43)$ showed: 0.43 (SE 1.29) $\mathrm{ml} \mathrm{O}_{2} \times \mathrm{min}^{-1} \times \mathrm{kg}^{-1}(95 \% \mathrm{CI}-2.18-3.05, \mathrm{P}=0.74)$ in car- diorespiratory fitness; -4.08 (SE 1.32) \%HRR (95\% CI $-6.78--1.39, \mathrm{P}<0.01)$ for aerobic workload; -2.08 (SE 2.61) bpm (95\% CI -7.37-3.20, $\mathrm{P}=0.43)$ for RHR; -8.01 (SE 1.73) bpm (95\% CI -11.54- -4.49, P<0.01) for SHR; 6.65 (SE 2.46) mmHg (95\% CI 1.68-11.63, $\mathrm{P}=0.01)$ for systolic BP; and 1.75 (SE 2.09) $\mathrm{mmHg}(95 \% \mathrm{CI}$ $-2.49-5.98, \mathrm{P}=0.41)$ for diastolic $\mathrm{BP}$. In the group of participants with a low level of aerobic workload at baseline $(\mathrm{N}=42)$, the results showed the following 3.95 (SE 1.47) $\mathrm{ml} \mathrm{O} \times \mathrm{min}^{-1} \times \mathrm{kg}^{-1}(95 \%$ CI $0.98-6.92, \mathrm{P}=0.01)$ in 
cardiorespiratory fitness; - 2.99 (SE 1.89) \%HRR (95\% CI -6.82-0.85, $\mathrm{P}=0.12$ ) for aerobic workload; -0.99 (SE 1.81) bpm (95\% CI $-4.65-2.66, \mathrm{P}=0.59)$ for RHR; 0.09 (SE 1.25) bpm (95\% CI -2.46-2.64, $\mathrm{P}=0.94)$ for SHR; 2.13 (SE 1.32) $\mathrm{mmHg}(95 \% \mathrm{CI}-0.53-4.80, \mathrm{P}=0.11)$ for systolic BP and -1.54 (SE 1.32) $\mathrm{mmHg}(95 \% \mathrm{CI}$ $-4.20-1.12, \mathrm{P}=0.25$ ) for diastolic $\mathrm{BP}$.

\section{Discussion}

The main results of this study among cleaners were that the aerobic exercise group, in comparison with the reference group, significantly improved cardiorespiratory fitness, aerobic workload, SHR and RHR, but increased systolic BP.

\section{Primary outcome}

Between-group comparisons including all randomized participants show an average improved cardiorespiratory fitness in the aerobic exercise group of 2.2 (SE $0.8) \mathrm{ml} \mathrm{O}_{2} \times \min ^{-1} \times \mathrm{kg}^{-1}$, corresponding to a $8.8 \%$ overall change compared to the randomized study population. In conclusion, the hypothesis regarding an enhanced cardiorespiratory fitness was not falsified. We consider this increase to be clinically relevant in this population because of their low baseline cardiorespiratory fitness [24.9 (SE 6.6) $\left.\mathrm{ml} \mathrm{O}_{2} \times \mathrm{min}^{-1} \times \mathrm{kg}^{-1}\right]$ and because their aerobic workload already exceeded recommended levels. Previous worksite interventions have found similar effect sizes on cardiorespiratory fitness in both sedentary and physically demanding jobs $(20,21)$.

In order to achieve improvements in cardiorespiratory fitness, an exercise intensity of $\geq 60 \%$ of HRR is required (36). The average HRR during the aerobic exercise sessions in this study was 67 (SE 13)\%, and $69 \%$ of the participants achieved an intensity of $\geq 60 \%$ of HRR. The observed low cardiorespiratory fitness of the cleaners [24.9 (SE 6.6) $\mathrm{O}_{2} \times \min ^{-1} \times$ $\left.\mathrm{kg}^{-1}\right]$ shows that the average relative aerobic workload during cleaning [31 (SE 7) \%HRR] is at or above recommended levels $(10,11)$, but at the same time not designed (eg, in terms of sufficient intensity) to improve their cardiorespiratory fitness (24). There were 32 30-minute aerobic exercise sessions over the 4-month period. This indicates that as long as there are short periods of sufficiently high aerobic intensity, relatively few aerobic exercise sessions can increase cardiorespiratory fitness in this population. In summary, aerobic exercise with high intensity during paid working hours seems to improve cardiorespiratory fitness among cleaners.

\section{Secondary outcomes}

The aerobic exercise group significantly reduced the aerobic workload by $11.3 \%$ compared to the reference group. Therefore, the second hypothesis regarding a decreased aerobic workload was not falsified. To our knowledge, this is the first RCT finding positive effects on aerobic workload objectively measured during days of normal work. The aerobic workload measured at baseline was relatively high [31 (SE 7) \%HRR]. Such high aerobic workload is reported to cause strain on the cardiovascular systems (11), potentially leading to progression of arteriosclerosis $(5,6)$ and relates to an increased risk of cardiovascular disease $(7,22)$. The observed reduction in aerobic workload of $11.3 \%$ can therefore be considered of clinical relevance. HRR can be reduced by increases in cardiorespiratory fitness, leading to a reduced RHR and SHR, or a decreased physical work demand (14) or the combination of these two. The reduction of the aerobic workload in this study can therefore be explained by the increased cardiorespiratory fitness and the reduced SHR (HRR $=\mathrm{HR}_{\text {max }}$ - SHR) (48). Because changes in aerobic workload are also influenced by changes in the physical work demands, a sensitivity analysis additionally adjusting for change in steps walked per hour of work was applied. This additional adjustment for change in steps did not substantially change the between-group difference of aerobic workload displayed in table 3 , model 2 . In summary, this study supports the classic work physiology notion that an aerobic exercise intervention increasing cardiorespiratory fitness can reduce the relative aerobic workload among blue-collar workers (54).

The reductions of $5.3 \%$ in RHR and $7.7 \%$ in SHR reject the null hypothesis of no effects of the aerobic exercise intervention on RHR and SHR (55). Reductions in both RHR and SHR can potentially reduce the risk of both CVD and all-cause mortality (55-57).

Systolic BP increased by 5.2 (SE 1.2) $\mathrm{mmHg}$ in the aerobic exercise group compared to 1.3 (SE 1.1) $\mathrm{mmHg}$ in the reference group (table 2), leading to a between-groups change of 3.6 (SE 1.3) $\mathrm{mmHg}$ in fully adjusted analyses (table 3, model 2). Therefore, the null hypothesis of no effects is rejected for blood pressure. This finding is in accordance with the previously stated hypothesis of Krause and colleagues (22) that high intensity physical exercise may cause an overload of the cardiovascular system when applied to workers with high levels of occupational physical activity, low cardiorespiratory fitness, and potentially limited ability for pauses and restitution.

An elevated systolic BP of 3.6 (SE 1.3) mmHg may appear relatively small, when applied to persons with low-to-normal BP (58). However, such an increase in BP is known to significantly increase CVD morbidity and 
mortality and, therefore, considered clinically relevant (59). Prediction of the long-term net cardiovascular health effects of this potentially harmful average BP change and the potential beneficial effects of an on average increased cardiorespiratory fitness is not possible with our data. It is conceivable that harmful and beneficial effects occur in different subsets of our population. Additional research is still needed to confirm if worksite aerobic exercise increases the systolic BP in other populations with high levels of occupational physical activity. Since ambulatory BP has been shown to be a better predictor of cardiovascular risk than resting $\mathrm{BP}$ (60), we plan additional analysis of our ambulatory BP data (35) and recommend that future studies with other populations should employ ambulatory BP measures.

To our knowledge, this study is the first to investigate the effects on BP of an aerobic exercise worksite intervention among cleaners. Our finding of an increased systolic BP is in contrast with previous exercise studies on BP among workers with high levels of occupational physical activity (20). The different effect in our study may be explained by the low cardiorespiratory fitness in our study population, making the participants less able to restitute from the additional aerobic exercise and, therefore, more susceptible to a cardiovascular overload. Of particular interest for interpretation of the study findings, the sub-group analyses stratified on aerobic workload at baseline showed that the participants exposed to a high aerobic workload ( $\geq 30 \%$ HRR during working hours) experienced a very strong increase in systolic BP of 6.5 (SE 2.5) $\mathrm{mmHg}(95 \% \mathrm{CI} 1.7-11.6, \mathrm{P}=0.01)$ from the aerobic exercise intervention, while the participants exposed to a low aerobic workload $(<30 \%$ HRR during working hours) experienced a somewhat lower increase in systolic BP of 2.1 (SE $1.3 \mathrm{mmHg}$ (95\% CI -0.5-4.8, $\mathrm{P}=0.11$ ). This finding supports the interpretation that the observed increased systolic BP in the intervention group could be explained by a cardiovascular overload from the aerobic exercise. However, because this analysis was not pre-planned, and the study was not designed to have sufficient power to investigate sub-group effects, these results should be interpreted with precaution.

The finding of an increased systolic BP in this single intervention is not enough evidence to draw general conclusions and recommendations. Therefore, it is important that this unintended adverse effect of this intervention will be monitored in additional future RCT among blue-collar workers. To reduce misclassification of $\mathrm{BP}$, future measurements should be based on more frequent measures, ideally using 24-hour measures of ambulatory BP.

\section{Strengths and limitations of the study}

The cluster RCT design is a methodological strength reducing possible bias and contamination. Also the intention-to-treat analysis is a methodological strength reducing possible bias (61). Additionally, the external validity was enhanced by the creation of an aerobic exercise and reference group at each enrolled company. The study was sufficiently powered to detect clinically relevant changes. The frequency and intensity of the exercise training and all outcomes of the study were objectively measured, thereby decreasing the potential of self-reporting and selection bias. The mixed-model analysis is a strength when evaluating repeated measurements observations with observations missing at random, since the mixed-model analysis enables use of information from all observations without imputing missing observations (52). Regarding the intervention, the modified intervention mapping approach (35) is a strong feature since the intervention is tailored specifically to the individual needs and wishes of the participating company and its employees.

The convenience sampling of only three companies in the area of Copenhagen, Denmark, limits the generalizability of the findings.

Randomization was only partly successful, our multivariate analyses detected substantial amounts of residual confounding in effect measures in the process of adjusting for confounders. Without additional adjustment for age, sex, daily use of antihypertension and/or heart medication, smoking status, fitness, and baseline leisure-time physical activity in multivariate analyses, confounding by these factors would have obscured a large part of the intervention effects as can be seen by comparing effect sizes in model 2 against model 1 , showing differences of up to $444 \%$. Although there may still be residual confounding by other unknown factors, our multivariate analyses reduced potential confounding bias substantially.

Participants lost to follow-up had a lower cardiorespiratory fitness, higher mean aerobic workload and walked less during working hours at baseline compared to participants not lost to follow-up, causing a selection bias towards a more healthy population being followed up. In the aerobic exercise and reference groups, respectively, 19 and 15 were lost to follow-up (figure 1), this percentage (29\%) of drop out is less than the expected $30 \%$ in our power calculations (39). No significant between-group differences were found among those lost to follow-up.

Missing data (missing not at random) occurred due to exclusions. At the cardiorespiratory fitness test, 18 (32\%) participants were excluded at baseline and 10 $(23 \%)$ at follow-up in the aerobic exercise group and $12(20 \%)$ at baseline and $12(27 \%)$ at follow-up in the reference group.

In the aerobic exercise group, $17(30 \%)$ participants at baseline and $14(37 \%)$ at follow-up, and 14 (24\%) participants at baseline and $20(45 \%)$ at follow-up in the 
reference group, did not have sufficiently high quality of data or were not mounted with the Actiheart.

Altogether, almost one fourth of the study population was excluded from testing possibly leading to a differential selection bias towards better outcomes in a more healthy population. On the other hand, the larger benefits in terms of enhanced cardiorespiratory fitness appeared among those with medication for pre-existing hypertension or heart disease. Due to some differences in missing data between groups, at baseline and follow-up, the mixed-model analysis was applied, since it allows an intention-to-treat analysis with missing observations (62).

Measurement of BP holds a large variability and is influenced by the context (eg, "white-coat hypertension"). However, large measurement variability typically increases random error and widens CI, ie, increases the risk for a type II error. Therefore, large measurement variability tends to bias results towards the null hypothesis and is not expected to cause a significant spurious effect in any one direction. Despite the small sample size in this RCT study, the measured BP effects were within $95 \% \mathrm{CI}$ and thus do not indicate a high probability of such errors. Moreover, adjustment for several potential confounders makes it unlikely that the results were biased by confounding factors. For these reasons, it seems inappropriate to disregard the findings as systematically biased, and there is no indication of any differential misclassification bias that could possibly lead to a spurious increase in BP in the aerobic exercise group only.

\section{Practical implications}

Cleaners suffer from an increased risk of CVD $(30,31)$, partially due to their low cardiorespiratory fitness and high aerobic workload $(7,24)$. In fact, the extensive objective measurements revealed that more than half $(51 \%)$ of our study population exceeded recommended levels of relative aerobic workload during working hours at baseline. Previous research has linked higher levels of aerobic workload with accelerated progression of atherosclerosis (22) and incidence of myocardial infarction (7). Clearly, there is a need to develop interventions that safely reduce aerobic workload and cardiovascular risk among high-risk occupational groups experiencing a high level of occupational physical activity (3).

The present study shows that the aerobic exercise worksite intervention improved cardiorespiratory fitness and most of the other measured cardiovascular risk factors with only 30 minutes of aerobic exercise twice a week for four months. The improvement in cardiorespiratory fitness, aerobic workload, RHR and SHR may reduce the risk of all-cause as well as CVD mortality $(3,7,26,56,57)$. On the other hand, the intervention significantly increased systolic BP, which may result in an increased risk of CVD and all-cause mortality (59, 63). Additional research is needed in order to provide effective and safe recommendations for how to promote cardiovascular health by aerobic exercise among workers with high relative aerobic workload and low cardiorespiratory fitness.

\section{Concluding remarks}

Based on a cluster-randomized design and objective data, this study indicates that a worksite aerobic exercise intervention among cleaners leads to improved cardiorespiratory fitness as well as reduced aerobic workload, RHR and SHR, but increases systolic BP. Accordingly, it seems like aerobic exercise induces several beneficial cardiovascular physiological effects but also one potentially harmful effect. Therefore, recommendations of aerobic exercise should take into consideration the potential cardiovascular overload of workers with high levels of occupational physical activity. Due to these contrasting findings, further studies are needed before recommendations with respect to aerobic exercise for workers with high levels of occupational physical activity can be made.

\section{Conflict of interest}

The authors declare no conflict of interest.

\section{References}

1. Li J, Loerbroks A, Angerer P. Physical activity and risk of cardiovascular disease: what does the new epidemiological evidence show? Curr Opin Cardiol. 2013;28:575-83. http:// dx.doi.org/10.1097/HCO.0b013e328364289c.

2. Holtermann A, Mortensen OS, Søgaard K, Gyntelberg F, Suadicani P. Risk factors for ischaemic heart disease mortality among men with different occupational physical demands. A 30-year prospective cohort study. BMJ Open. 2012;2:e000279. http://dx.doi.org/10.1136/bmjopen-2011-000279.

3. Holtermann A, Mortensen OS, Burr H, Søgaard K, Gyntelberg F, Suadicani P. Physical demands at work, physical fitness, and 30-year ischaemic heart disease and all-cause mortality in the Copenhagen Male Study. Scand J Work Environ Health. 2010;36:357-65. http://dx.doi.org/10.5271/sjweh.2913.

4. Louhevaara V. Job Demands and Physical Fitness in The Occupational Ergonomics Handbook. Boca Raton, FL: CRC Press LLC; 1999. p. 261-73.

5. Glagov S, Zarins C, Giddens DP, Ku DN. Hemodynamics and Atherosclerosis - Insights and Perspectives Gained from Studies of Human Arteries. Arch Pathol Lab Med 1988;112:1018-31. 
6. Sukhova GK, Schonbeck U, Rabkin E, Schoen FJ, Poole AR, Billinghurst RC, et al. Evidence for increased collagenolysis by interstitial collagenases- 1 and -3 in vulnerable human atheromatous plaques. Circulation. 1999;99:2503-9. http:// dx.doi.org/10.1161/01.CIR.99.19.2503.

7. Krause N, JB Brand, A Onyebuchi, J Kauhanen. Occupational physical activity and 20-year incidence of acute myocardial infarction: results from the Kuopio Ischemic Heart Disease Risk Factor Study. Scand J Work Environ Health. 2015; 41(2):124-139. http://dx.doi.org/10.5271/sjweh.3476

8. Ilmarinen J, Tuomi K, Klockars M. Changes in the work ability of active employees over an 11-year period. Scand J Work Environ Health. 1997;23 Suppl 1:49-57.

9. Karlqvist L, Leijon O, Härenstam A. Physical demands in working life and individual physical capacity. Eur J Appl Physiol. 2003;89:536-47. http://dx.doi.org/10.1007/s00421003-0832-4.

10. Bonjer FH.Parmeggiana L. editor. Encyclopedia of Occupational Health and Safety. Geneva: International Labour Organisation; 1971.

11. Wu HC, Wang MJJ. Relationship between maximum acceptable work time and physical workload. Ergonomics. 2002;45:280 9. http://dx.doi.org/10.1080/00140130210123499.

12. Åstrand PO, Rodahl K, Dahl HA, Stromme SB. Textbook of Work Physiology. Maidenhead, UK: McGraw-Hill Book Company; 1986.

13. Gupta N, Jensen BS, Søgaard K, Carneiro IG, Christiansen CS, Hanisch C, et al. Face validity of the single work ability item: comparison with objectively measured heart rate reserve over several days. Int J Environ Res Public Health. 2014;11:533348. http://dx.doi.org/10.3390/ijerph110505333.

14. Tanaka H, Monahan KD, Seals DR. Age-predicted maximal heart rate revisited. J Am Coll Cardiol. 2001;37:153-6. http:// dx.doi.org/10.1016/S0735-1097(00)01054-8.

15. Pollock ML, Foster C, Rod JL, Wible G. Comparison of methods for determining exercise training intensity for cardiac patients and healthy adults. Adv Cardiol. 1982;31:129-33.

16. Gram B, Holtermann A, Søgaard K, Sjøgaard G. Effect of individualized worksite exercise training on aerobic capacity and muscle strength among construction workers-a randomized controlled intervention study. Scand J Work Environ Health. 2012;38:467-75. http://dx.doi.org/10.5271/ sjweh.3260.

17. Grandjean PW, Oden GL, Crouse SF, Brown JA, Green JS Lipid and lipoprotein changes in women following 6 months of exercise training in a worksite fitness program. J Sports Med Phys Fitness. 1996;36:54-9.

18. Gerdle B, Brulin C, Elert J, Eliasson P, Granlund B. Effect of a general fitness program on musculoskeletal symptoms, clinical status, physiological capacity, and perceived work environment among home care service personnel. J Occup Rehabil. 1995;5:1-16. http://dx.doi.org/10.1007/ BF02117816.

19. Härmä MI, Ilmarinen J, Knauth P, Rutenfranz J, Hanninen O. Physical training intervention in female shift workers:
I. The effects of intervention on fitness, fatigue, sleep, and psychosomatic symptoms. Ergonomics. 1988;31:39-50. http:// dx.doi.org/10.1080/00140138808966647.

20. Proper KI, Koning M, Van der Beek AJ, Hildebrandt VH, Bosscher RJ, Van Mechelen W. The effectiveness of worksite physical activity programs on physical activity, physical fitness, and health. Clin J Sport Med. 2003;13:106-17. http:// dx.doi.org/10.1097/00042752-200303000-00008.

21. Conn VS, Hafdahl AR, Cooper PS, Brown LM, Lusk SL. Meta-analysis of workplace physical activity interventions. Am J Prev Med. 2009;37:330-9. http://dx.doi.org/10.1016/j. amepre.2009.06.008.

22. Krause N, Brand RJ, Kaplan GA, Kauhanen J, Malla S, Tuomainen TP, et al. Occupational physical activity, energy expenditure and 11-year progression of carotid atherosclerosis. Scand J Work Environ Health. 2007;33:405-24. http://dx.doi. org/10.5271/sjweh.1171.

23. Holtermann A, Mortensen OS, Burr H, Søgaard K, Gyntelberg F, Suadicani P. The interplay between physical activity at work and during leisure time - risk of ischemic heart and allcause mortality in middle-aged Caucasian men. Scand J Work Environ Health. 2009;35:466-74. http://dx.doi.org/10.5271/ sjweh.1357.

24. Korshøj M, Krustrup P, Jespersen T, Søgaard K, Skotte JH, Holtermann A. A 24-h assessment of physical activity and cardio-respiratory fitness among female hospital cleaners: a pilot study. Ergonomics. 2013;56:935-43. http://dx.doi.org/1 0.1080/00140139.2013.782427.

25. Jørgensen MB, Rasmussen CDN, Carneiro IG, Flyvholm MA, Olesen K, Ekner D, et al. Health disparities between immigrant and Danish cleaners. Int Arch Occup Environ Health. 2011;84(6):665-74. http://dx.doi.org/10.1007/s00420-010$0607-2$

26. Holtermann A, Burr H, Hansen JV, Krause N, Søgaard K, Mortensen OS. Occupational physical activity and mortality among Danish workers. Int Arch Occup Environ Health. 2012;85(3):305-10. http://dx.doi.org/10.1007/s00420-0110668-x.

27. Søgaard K, Blangsted AK, Herod A, Finsen L. Work Design and the Labouring Body: Examining the Impacts of Work Organization on Danish Cleaners' Health. Antipode: 2006. http://dx.doi.org/10.1111/j.0066-4812.2006.00596.x.

28. Unge J, Ohlsson K, Nordander C, Hansson GA, Skerfving S, Balogh I. Differences in physical workload, psychosocial factors and musculoskeletal disorders between two groups of female hospital cleaners with two diverse organizational models. Int Arch Occup Environ Health. 2007;81:209-20. http://dx.doi.org/10.1007/s00420-007-0208-x.

29. Zock JP. World at work: Cleaners. Occup Environ Med. 2005;62:581-4. http://dx.doi.org/10.1136/oem.2004.015032.

30. Sjögren B, Fredlund P, Lundberg I, Weiner J. Ischemic heart disease in female cleaners. Int $J$ Occup Environ Health. 2003;9:134-7. http://dx.doi.org/10.1179/oeh.2003.9.2.134.

31. Zöller B, Li X, Sundquist J, Sundquist K. Socioeconomic and occupational risk factors for venous thromboembolism 
in Sweden: a nationwide epidemiological study. Thromb Res. 2012;129:577-82. http://dx.doi.org/10.1016/j. thromres.2011.07.050.

32. Søgaard K, Fallentin N, Nielsen J. Work load during floor cleaning. The effect of cleaning methods and work technique. Eur J Appl Physiol Occup Physiol. 1996;73:73-81. http:// dx.doi.org/10.1007/BF00262812.

33. Søgaard K, Laursen B, Jensen BR, Sjøgaard G. Dynamic loads on the upper extremities during two different floor cleaning methods. Clin Biomech. 2001;16:866-79. http://dx.doi. org/10.1016/S0268-0033(01)00083-3.

34. Woods V, Buckle P. Musculoskeletal ill health amongst cleaners and recommendations for work organisational change. Int J Ind Erg. 2006;36:61-72. http://dx.doi.org/10.1016/j. ergon.2005.08.001.

35. Korshøj M, Krustrup P, Jørgensen MB, Prescott E, Hansen AM, Kristiansen J, et al. Cardiorespiratory fitness, cardiovascular workload and risk factors among cleaners; a cluster randomized worksite intervention. BMC Public Health. 2012;12:645. http://dx.doi.org/10.1186/1471-2458-12-645.

36. Davies CTM, Knibbs AV. The training stimulus. The effects of intensity, duration and frequency of effort on maximum aerobic power output. Int $\mathrm{Z}$ angew Physiol Arbeitsphysiol. 1971;29:299-305.

37. Bartholomew LK, Parcel GS, Kok G. Intervention mapping: a process for developing theory- and evidence-based health education programs. Health Educ Behav. 1998;25:545-63. http://dx.doi.org/10.1177/109019819802500502.

38. O’Brien E, Waeber B, Parati G, Staessen J, Myers M. Blood pressure measuring devices: recommendations of the European Society of Hypertension. Br J Sports Med. 2001;322:531-6.

39. Borg GAV. Physical performance and perceived exertion. Lund: CWK Glerup; 1962.

40. Saltin B, Grimby G. Physiological analysis of middle-aged and old former athletes. Comparison with still active athletes of the same ages. Circulation. 1968;38:1104-15. http://dx.doi. org/10.1161/01.CIR.38.6.1104.

41. Bjørner JB, Wallenstein GV, Martin MC, Lin P, BlaisdellGross B, Tak PC, et al. Interpreting score differences in the SF-36 Vitality scale: using clinical conditions and functional outcomes to define the minimally important difference. Curr Med Res Opin. 2007;23:731-9. http://dx.doi. org/10.1185/030079907X178757.

42. Canoy D. Distribution of body fat and risk of coronary heart disease in men and women. Curr Opin Cardiol. 2008;23:5918. http://dx.doi.org/10.1097/HCO.0b013e328313133a.

43. Han TS, Sattar N, Lean M. ABC of obesity. Assessment of obesity and its clinical implications. BMJ. 2006;333:695-8. http://dx.doi.org/10.1136/bmj.333.7570.695.

44. Aadahl M, Zacho M, Linneberg A, Thuesen BH, Jørgensen T. Comparison of the Danish step test and the watt-max test for estimation of maximal oxygen uptake: the Health2008 study. Eur J Prev Cardiol. 2013;20:1088-94. http://dx.doi. org/10.1177/2047487312462825.

45. Barreira TV, Kang M, Caputo JL, Farley RS, Renfrow MS.
Validation of the Actiheart Monitor for the Measurement of Physical Activity. Int J Exer Sci. 2009;2(1):60-71.

46. Kristiansen J, Korshøj M, Skotte JH, Jespersen T, Søgaard K, Mortensen OS, et al. Comparison of two systems for long-term heart rate variability monitoring in free-living conditions - a pilot study. Biomed Eng Online. 2011;27:10.

47. Brage S, Brage N, Franks PW, Ekelund U, Wareham NJ. Reliability and validity of the combined heart rate and movement sensor Actiheart. Eur J Clin Nutr. 2005;59:561-70. http://dx.doi.org/10.1038/sj.ejcn.1602118.

48. Karvonen J, Vuorimaa T. Heart rate and exercise intensity during sports activities. Practical application. Sports Med. 1988;5:303-11. http://dx.doi.org/10.2165/00007256198805050-00002.

49. Brage S, Brage N, Franks PW, Ekelund U, Wong MY, Andersen LB, et al. Branched equation modeling of simultaneous accelerometry and heart rate monitoring improves estimate of directly measured physical activity energy expenditure. J Appl Physiol. 2004;96:343-51. http://dx.doi.org/10.1152/ japplphysiol.00703.2003.

50. Makowiec-Dabrowska T, Bortkiewicz A, Radwan-Wlodarczyk Z, Koszada-Wlodarczyk W. Physiological reaction to workload in women performing manual or mental work. Pol J Occup Med Environ Health. 1992;5:257-64.

51. Skotte J, Korshøj M, Kristiansen J, Hanisch C, Holtermann A. Detection of physical activity types using triaxial accelerometers. J Phys Act Health. 2014;11:76-84. http:// dx.doi.org/10.1123/jpah.2011-0347.

52. White IR, Carpenter J, Horton NJ. Including all individuals is not enough: lessons for intention-to-treat analysis. Clin Trials. 2012;9:396-407. http://dx.doi. org/10.1177/1740774512450098.

53. Altman DG. Missing outcomes in randomized trials: adressing the dilemma. Open Medicine. 2009;3:51-3.

54. Ilmarinen J. Physical requirements associated with the work of aging workers in the European Union. Exp Aging Res. 2002;28:7-23. http://dx.doi.org/10.1080/036107302753365 513.

55. Jensen MT, Suadicani P, Hein HO, Gyntelberg F. Elevated resting heart rate, physical fitness and all-cause mortality: a 16-year follow-up in the Copenhagen Male Study. Heart. 2013;99:882-7. http://dx.doi.org/10.1136/ heartjnl-2012-303375.

56. Fox K, Borer JS, Camm AJ, Danchin N, Ferrari R, Lopez Sendon JL, et al. Resting heart rate in cardiovascular disease. J Am Coll Cardiol. 2007;50:823-30. http://dx.doi. org/10.1016/j.jacc.2007.04.079.

57. Cooney MT, Vartiainen E, Laatikainen T, Juolevi A, Dudina A, Graham IM. Elevated resting heart rate is an independent risk factor for cardiovascular disease in healthy men and women. Am Heart J. 2010;159:612-9. http://dx.doi.org/10.1016/j. ahj.2009.12.029.

58. O’Brien E, Asmar R, Beilin L, Imai Y, Mancia G, Mengden $\mathrm{T}$, et al. Practice guidelines of the European Society of Hypertension for clinic, ambulatory and self blood pressure measurement. J Hypertens. 2005;23:697-701. 
http://dx.doi.org/10.1097/01.hjh.0000163132.84890.c4.

59. He J, Whelton PK. Elevated systolic blood pressure and risk of cardiovascular and renal disease: overview of evidence from observational epidemiologic studies and randomized controlled trials. Am Heart J. 1999;138:211-9. http://dx.doi. org/10.1016/S0002-8703(99)70312-1.

60. Hansen TW, Kikuya M, Thijs L, Björklund-Bodegård K, Kuznetsova T, Ohkubo T, et al. Prognostic superiority of daytime ambulatory over conventional blood pressure in four populations: a meta-analysis of 7,030 individuals. $\mathrm{J}$ Hypertens. 2007;25:1554-64. http://dx.doi.org/10.1097/ HJH.0b013e3281c49da5.
61. Detry MA, Lewis RJ. The intention-to-treat principle: how to assess the true effect of choosing a medical treatment. JAMA. 2014;312:85-6. http://dx.doi.org/10.1001/jama.2014.7523.

62. Twisk J, de BM, de VW, Heymans M. Multiple imputation of missing values was not necessary before performing a longitudinal mixed-model analysis. J Clin Epidemiol. 2013;66:1022-8. http://dx.doi.org/10.1016/j. jclinepi.2013.03.017.

63. Cornelissen VA, Smart NA. Exercise training for blood pressure: a systematic review and meta-analysis. J Am Heart Assoc. 2013;2:e004473. http://dx.doi.org/10.1161/ JAHA.112.004473.

Received for publication: 22 September 2014 